\title{
Political advocacy in pharmacy: challenges and opportunities
}

This article was published in the following Dove Press journal:

Integrated Pharmacy Research and Practice

30 September 2014

Number of times this article has been viewed

\section{Dorie E Apollonio}

Department of Clinical Pharmacy, University of California, San Francisco, San Francisco, CA, USA
Correspondence: Dorie E Apollonio University of California, San Francisco, 3333 California Street, Suite 420, San Francisco, CA 94143-0613, USA

Tel +l 4I5 5021942

Fax +l 4I5 5020792

Email dorie.apollonio@ucsf.edu
Abstract: Many pharmacists have expressed a desire to become more involved in patient care, in part by being compensated for patient counseling, as well as by providing services traditionally offered by physicians and nurse practitioners. Recent efforts to develop collaborative care models, as well as major restructurings of US health insurance coverage, provide a unique opportunity for pharmacists to become recognized as independent health care providers and be reimbursed as primary care providers. Achieving that goal would require addressing advocacy challenges familiar to other health care professionals who have achieved provider status under existing reimbursement rules. Historically, political advocacy has not been a major part of pharmacy practice, or even viewed as necessary. However, pharmacists would be more politically effective with a single organization to speak for them as a profession, and with further education in advocacy.

Keywords: primary care provider, advocacy, pharmacy practice, patient care, reimbursement

\section{The relevance of advocacy in changing pharmacy practice}

Pharmacists in the US increasingly face tension between how they are paid, which is often by filling prescriptions, and what they claim they want to do, which is to counsel patients and manage medications. Historically, filling prescriptions allowed time to counsel patients without separate reimbursement, but cost pressures on health care practice have made the provision of unreimbursed services increasingly difficult. This disjuncture between pharmacists' expertise and the ways that they are reimbursed suggests two options: pharmacists could reassess their training and expectations to do only the jobs they are currently reimbursed for, or pharmacists could advocate for an expanded practice role. Without reimbursement for primary care services, cost pressures will make the historically unpaid practice of counseling patients regarding medications increasingly difficult. However, reimbursement for health care services is based on coverage decisions made by government and changing government decisions requires advocating for change. This paper considers the challenges and opportunities for pharmacists who seek to advocate for an expanded practice role.

Advocacy, especially political advocacy, is often viewed as a form of persuasion or influence, but it is also a form of education. ${ }^{1}$ Historically, political advocacy has not been a major part of pharmacy practice, or even viewed as necessary. ${ }^{1}$ If pharmacists wish to continue to be able to counsel patients effectively, however, political advocacy deserves to play a much larger role for pharmacists. 
Practitioners and insurance plans in the US have committed to developing more collaborative forms of care, providing new opportunities to pharmacists, who have expressed desire to be more involved in direct patient care and spend less time dispensing medications. Increasing evidence suggests that allowing pharmacists to serve as health care providers can improve patient care and increase cost-effectiveness. Changes in US health care coverage offer an unprecedented opportunity to establish new ways for pharmacists and other health care professionals to work together. In response to these changes, a few schools of pharmacy have begun to develop programs to teach new pharmacists to become effective advocates. These skills have both professional and clinical implications.

These new opportunities come packaged with significant challenges for pharmacists seeking to find a place in redesigned health care systems. Pharmacists face increasing economic pressures that compel them to spend less time in contact with patients and more time dispensing medications. Effective advocacy to allow pharmacists to be reimbursed for direct patient care is limited by the profession's relative political inexperience and lack of a unified advocacy group. The organizations representing pharmacists as a profession are fragmented and lack a cohesive voice. In addition, advocacy for pharmacy as a profession can at times be confused with advocacy for the pharmaceutical industry, even though these groups often have different goals. Finally, pharmacists as a profession have emphasized selling products rather than patient care, and this emphasis has in some cases undercut their professional credibility to act as health care providers.

Political advocacy is an effective strategy to change health care policy and health care professionals' scope of practice. ${ }^{2}$ Physicians, and more recently nurse practitioners, have successfully used political advocacy in the past to obtain reimbursement for their services and modify popular perceptions of their professions. These changes allowed them to become independent and self-regulating professionals focused on providing expertise to patients. Pharmacists have repeatedly expressed desire for the same kind of independence and for new opportunities to provide direct patient care. In the highly regulated area of health care, making this transition will require educating policymakers about the benefits of including pharmacists on collaborative health care teams.

\section{Opportunities in pharmacy practice Health care is becoming more collaborative}

Health care is shifting away from the single provider model based largely on physician-patient relationships.
Since 2005, England and Wales have allowed pharmacists to be reimbursed under the National Health Service as providers for certain services. ${ }^{3}$ In the US, multiple states have also passed laws allowing pharmacists provider status, although these laws rarely allow pharmacists to bill insurers for the provision of these services. ${ }^{4,5}$

Historically, pharmacists have served as the providers of first resort, assessing whether individuals needed to seek medical diagnosis and treatment. ${ }^{6}$ Multiple studies report that pharmacists would prefer to spend more time in direct patient care and less time dispensing medications. ${ }^{7-9}$ Although there are increasing efforts to develop collaborative health care models, it is not yet clear what roles different health care professionals will play. In many cases, nurse practitioners and physician assistants take over the "physician extender" role, rather than other kinds of health professionals such as pharmacists. ${ }^{10}$

In the US, this use of nurse practitioners and physician assistants reflects the fact that it is possible to bill insurance for services they provide. The same is not true of pharmacists or pharmacist technicians, who are still paid for dispensing medications rather than providing services. In addition, economic pressures on pharmacies that demand that pharmacists fill more prescriptions in less time to maintain the same practice income, and the increasing role of chain pharmacies, have reduced the time that community pharmacists can spend on direct patient care. Although inpatient pharmacists have more opportunities to spend time with patients, they can still be drawn into spending time on dispensing products because that is how pharmacists are reimbursed. A new collaborative model of health care could offer opportunities for physicians to focus on diagnosis and for pharmacists to take over medication therapy management.

\section{Including pharmacists on health care teams can improve patient care and reduce costs}

Pharmacists may hold provider status as part of a health care team in a single unit, such as oncology, in an individual hospital, but few places offer consistent pharmacist services across multiple sites or disease conditions. The research that has been completed on health outcomes when pharmacists provide other services is, as a result, difficult to generalize. However, systematic reviews suggest that pharmacist interventions resulted in improvement in clinical outcomes, although improvements were not always statistically significant. ${ }^{11,12}$

Unfortunately, typical measures of patient care may be limited when judging the contributions made by pharmacists 
because of their status as providers of first resort. Research from the UK suggests that consultation with a pharmacist may in some cases lead patients to seek the care of a physician, which increases costs, or to be readmitted to a hospital after discharge, which is generally considered to be a measure of poorer care. ${ }^{13}$ Yet, if patients are seeking appropriate care from physicians or need to be readmitted, these referrals may represent higher quality patient care or suggest the need to investigate discharge practices. These findings suggest that further research is needed to identify the best measures of quality of care for health care teams that include pharmacists.

Nonetheless, there is increasing evidence suggesting that even by traditional measures of cost-effectiveness and quality of care, including pharmacists in collaborative patient care can improve health outcomes and reduce costs. These studies provide justification for classifying pharmacists as providers and reimbursing them for their services. The finding that some pharmacist services may not be measured effectively by existing standards for quality of care suggests that advocacy for increased research in this area should also focus on identifying better metrics for what constitutes high quality and cost-effective care, and how to assign responsibility for health outcomes when multiple health care professionals work together.

\section{Changes in national health programs provide a window of opportunity to change practice}

Increasing health care costs have led a number of countries to reconsider how they provide care under national health insurance. Both dentists and pharmacists typically delegate routine work to technicians and focus on more difficult, complicated, or legally required tasks. Physicians, in contrast, have historically taken responsibility for multiple levels of care. In recent years, this has begun to change. Increasingly, nurse practitioners and physician assistants provide routine care for patients in physician practices. However, the increasing reliance on drug therapy for patient care has made medication therapy management, in consultation with pharmacists, increasingly important in the provision of care.$^{14}$ National health insurance plans have begun to experiment with delegating services such as tobacco cessation counseling and treatment to pharmacists, and allowing pharmacists to prescribe a limited set of medications as well as dispense them.

\section{Pharmaceutical schools have begun to teach advocacy as well as patient care}

Historically, pharmacists rarely engaged in political advocacy or perceived much reason to do so. ${ }^{1}$ As a result, the profession of pharmacy has failed to develop the skills and knowledge to be effective advocates - effective advocacy, like other expertise, is learned and can be taught. As many pharmacists have expressed increasing desire to move their practice focus away from exclusively dispensing products, however, it has become clear that new advocacy skills are necessary. Nurse practitioners battled for several years in the US to obtain provider status, making incremental gains before achieving national recognition. To make the same transition, pharmacists would need the same kinds of skills used by nurse practitioners, and by physicians before them. Political advocacy is an effective way to make policy changes. ${ }^{2}$

Pharmacy schools have proliferated in recent years, and one way that some programs have begun to provide differentiated education is the creation of new classes focusing on advocacy. ${ }^{1}$ Pharmacists increasingly need to advocate both for their own professional goals and for patients, who may need an expert to justify the reimbursement of a particular medication from an insurance provider. Advocacy skills can be applied to policy change, but they can also serve as a clinical tool. The extremely limited historical training in and use of advocacy by pharmacists means that the profession has enormous untapped resources. Expanding advocacy education for pharmacists beyond the current limited number of pilot programs would take advantage of this capacity.

\section{Challenges to effective advocacy Pharmacists are pushed away from provider roles}

Historically, the profession of pharmacy has been based around the provision of products rather than the provision of services. In the 1960s, pharmacy was classified by sociologists as a quasi-profession rather than a profession. ${ }^{15}$ Part of the justification was that pharmacy did not maintain control of its service, which was defined at the time as the provision of therapeutic drugs, given that these drugs were also available as samples from physicians. Product samples do not undercut a professional model based on the provision of medication services, but they do undercut a professional model based on restricted access to drugs. Other professional characteristics measured by sociologists that pharmacy lacked included self-governance (defined as status as a health care provider), consensus about their professional roles, and supplying "service or advice for a definite fee or salary." ${ }^{15}$ To some extent all of these issues persist to the present day.

Pharmacists are poorly integrated into the health system, in large part because the emphasis on products shifts the focus away from patients. ${ }^{16}$ Legally, in court cases addressing 
malpractice, pharmacists are primarily recognized as product dispensers rather than service providers. ${ }^{17}$ Although this legal status comes with reduced liability, it does not reflect what pharmacists report that they want to do with their time, or how pharmacy schools train them to provide patient care.

Multiple studies suggest that pharmacists prefer to spend their time providing patients with information rather than dispensing drugs, and that patients value primary care provided by pharmacists once they have experienced it..$^{7-9}$ However, pharmacists cannot provide additional services, particularly counseling, without the time and space to speak to patients, and both are increasingly rare. ${ }^{18}$ Community pharmacists may offer advice about medication, but they spend the majority of their time dispensing medications. ${ }^{19-21}$ Economic incentives, including the increasing pressure to fill more prescriptions in less time as the reimbursement rate for each individual prescription drops, make it even more difficult to spend time on other patient care services. ${ }^{22}$ The shift to mail order prescriptions may further exacerbate the problem, as mail order prescription adherence appears to be lower for some drugs, and phone counseling provided has been found less effective than in-person pharmacist interventions. ${ }^{23,24}$

\section{Pharmacist organizations are fragmented}

Advocacy organizations have dramatically different levels of political influence. Significantly, one powerful interest group may better represent an issue than a variety of less powerful groups. Before the 1980s, senior citizens represented almost $20 \%$ of the general US population, but were rarely recognized as a significant political force. Since then, AARP (formerly the American Association of Retired Persons) has become widely recognized as one of the most influential interest groups in American politics, and its continued influence lessens the need for multiple organizations to advocate for retirees. ${ }^{25}$ Similarly, in 1997, after years of efforts, nurse practitioners in the US successfully bid for provider status and direct reimbursement for services under Medicare after forming an umbrella organization to represent their interests as health care providers. ${ }^{26,27}$ For most interests, even controversial ones such as gun rights or tobacco, the existence of one or two peak organizations is an advantage.

Like these organizations, the pharmaceutical industry in the US operates under a large umbrella organization (Pharmaceutical Research and Manufacturers of America) that advocates for the industry's interests. ${ }^{28}$ Physicians have developed powerful trade associations that purport to represent them as a profession. ${ }^{29}$ Pharmacists as a profession, however, lack a single unifying organization. Instead, a multitude of groups seeks to represent the interests of different types of pharmacists. ${ }^{30}$ The absence of a single peak advocacy organization representing pharmacists as a profession limits the ability of policymakers to work with the profession - an agreement made with one organization may not be meaningful to other organizations, assuming that they are aware of it at all. Without a single organization representing the interests of pharmacists as a group, changes in health care laws and national insurance programs that would allow pharmacists to act as providers and bill for those services are likely to come slowly, if at all.

\section{Pharmaceutical organizations have different goals}

Although effective advocacy by pharmacists as a profession remains nascent, the pharmaceutical industry is viewed as enormously powerful, ${ }^{31}$ and is extremely well organized. In the absence of a strong professional organization, pharmaceutical industry groups are often conflated with pharmacist professional groups. ${ }^{30}$ The pharmaceutical industry and pharmacists as professionals may at times have similar goals, including investment in new drug development, and many pharmacists work directly for industry. However, the pharmaceutical industry is primarily interested in drug discovery, development, and manufacturing. ${ }^{32-35}$ In addition, on some policy issues the interests of pharmacists engaged in patient care may conflict directly with the interests of the pharmaceutical industry. Pharmaceutical companies typically seek to extend patent protections and delay the development and use of generic drugs, ${ }^{36,37}$ while pharmacists working directly with patients may prefer generic drugs, both to reduce patient costs and increase adherence. ${ }^{38}$

The existence of powerful pharmaceutical industry groups would have the potential to confuse policymakers and consumers even if pharmacists had a strong and unified organization to represent them as professionals. In the absence of such an organization, the issues supported by the pharmaceutical industry are at times viewed as the issues supported by pharmacists. ${ }^{30}$

\section{Conflicts of interest undermine public trust in pharmacy}

Although pharmacists, like other health practitioners, are generally viewed as trustworthy, positive perceptions of pharmacists are tarnished by the history of pharmacies selling tobacco and alcohol in addition to therapeutic drugs. In the US, where many pharmacies still sell tobacco and alcohol, the sales of these products compromise the perception of 
pharmacists as health providers. ${ }^{39-44}$ Moreover, pharmacists who have spent more time in roles where they spend most of their time dispensing products are less likely to perceive that they should take ethical responsibility for patients. ${ }^{45}$ These factors can make the sale of tobacco and alcohol seem unobjectionable to pharmacies, who view them only as a different type of product that a pharmacy could supply. Consumers, however, find it difficult to accept pharmacists as health professionals if they are simultaneously providing therapeutic drugs and drugs that cause harm. Eliminating tobacco and alcohol sales in pharmacies could eliminate the problem, but as long as consumers remember a time that pharmacies once supplied those products, the impact on the profession may linger.

\section{Strategies for the future}

Pharmacists in the US have expressed the desire to provide primary care beyond dispensing medications, and currently have a unique opportunity to establish new practice roles through new reimbursement models. Making these changes will require addressing and overcoming historical reimbursement models that segregate pharmacists into a role that often restricts them to dispensing medications.

Advocates for expanding the role of pharmacy suggest that separating pharmacist services from medication dispensing is critical to making this change. ${ }^{16}$ Dispensing of medications could be taken over to some extent by automation and by pharmacy technicians, and given cost pressures on pharmacies, which have increased as the payments for filling prescriptions have dropped, some of this shift has already started to happen. Making these two functions distinct would also help reduce perceptions of conflict of interest in pharmacy, which stem in part from pharmacy sales of tobacco, a known health hazard that is the leading cause of preventable death. Addressing perceived conflicts of interest has become a major issue in medicine. It may be an equally major issue in pharmacy as long as patient care is linked with selling products. ${ }^{30}$

A shift to a health care system where pharmacists are routinely reimbursed for providing medication therapy management would require policy change at the national level. Pharmacist organizations currently appear too fragmented to effectively advocate for these changes. In the absence of a strong professional pharmacist presence in political advocacy, the pharmaceutical industry has become the face of pharmacy for many policymakers and consumers. The advocacy training that has begun in pharmacy schools might productively focus on integrating existing pharmacist groups into a single peak organization that could effectively speak for pharmacists as a profession. The history of nurse practitioners, who developed a single organization in the 1990s to advocate for their provider status and reimbursement, offers a useful parallel for pharmacists seeking the same goals.

The American Association of Colleges of Pharmacy recently stated that its main policy issues were payment policy, interprofessional education, medication adherence, and education quality. ${ }^{46}$ The first three of these goals could all be addressed by establishing a new model of collaborative care. Changes in payment policy that allowed pharmacists to be reimbursed for medication therapy management would allow pharmacists to become part of interprofessional health care teams. Primary care provided by pharmacists may also improve medication adherence and health care outcomes. Reaching this collaborative care model may require improving the quality of education for pharmacists by developing the advocacy skills of new pharmacists.

Political advocacy has not historically been considered relevant to pharmacy practice. Under current health care systems, however, policymaking and advocacy are critical to health care. Health care coverage has become national in scope, and because coverage is partially funded by taxpayers and regulated by governments, decisions about what to cover have become political decisions as well as clinical decisions. Like nurses and doctors before them, pharmacists can become relevant to health care systems in part by becoming credible advocates for the value that the profession of pharmacy adds to patient care.

Pharmacists currently have an unprecedented opportunity to educate policymakers and other providers and make collaborative health care more expansive. They also have enormous untapped capacity to make these changes happen. Although the challenges are significant, they are not unique: every effective organization started from a position of inexperience and grew toward more successful advocacy. Addressing the challenges of the profession and creating a unified voice for pharmacists as a profession would be a major step toward making pharmacists independent health care providers who are paid for providing expertise.

\section{Acknowledgments}

Dr Apollonio's research was supported by National Cancer Institute \#1K07CA140236.

\section{Disclosure}

The author reports no conflicts of interest in this work. 


\section{References}

1. Gohlke AL, Murphy KM, Cannell ME, Ray DB, Burnworth MJ. Igniting the fire within: a primer on political advocacy for pharmacy professionals. J Pharm Pract. 2013;26(3):165-170.

2. Smith RA. Advocacy, interpretation, and influence in the US. Congress. Am Polit Sci Rev. 1984;78(1):44-63.

3. Richardson E, Pollock AM. Community pharmacy: moving from dispensing to diagnosis and treatment. BMJ. 2010;340:c2298.

4. Thompson CA. California bill would accord pharmacists provider status. Am J Health Syst Pharm. 2013;70(10):839-840.

5. State provider status legislation and initiatives [webpage on the Internet]. Alexandria, VA: American Society of Consultant Pharmacists; 2014. Available from: https://www.ascp.com/providerstatus/states. Accessed June 20, 2014

6. Gallagher KF, Zander LI. General practitioner and the pharmacist. Br Med J (Clin Res Ed). 1983;287(6389):397-398.

7. Schommer JC, Pedersen CA, Gaither CA, Doucette WR, Kreling DH, Mott DA. Pharmacists' desired and actual times in work activities: evidence of gaps from the 2004 National Pharmacist Workforce Study. J Am Pharm Assoc (2003). 2006;46(3):340-347.

8. Lea VM, Corlett SA, Rodgers RM. Workload and its impact on community pharmacists' job satisfaction and stress: a review of the literature. Int J Pharm Pract. 2012;20(4):259-271.

9. Laliberte MC, Perreault S, Damestoy N, Lalonde L. Ideal and actual involvement of community pharmacists in health promotion and prevention: a cross-sectional study in Quebec, Canada. BMC Public Health. 2012;12:192.

10. Fincham JE, Ahmed A. Dramatic need for cooperation and advocacy within the academy and beyond. Am J Pharm Educ. 2012;76(1):1.

11. Nkansah N, Mostovetsky O, Yu C, et al. Effect of outpatient pharmacists' non-dispensing roles on patient outcomes and prescribing patterns [review]. Cochrane Database Syst Rev. 2010;7:CD000336.

12. Pande S, Hiller JE, Nkansah N, Bero L. The effect of pharmacistprovided non-dispensing services on patient outcomes, health service utilisation and costs in low- and middle-income countries [review]. Cochrane Database Syst Rev. 2013;2:CD010398.

13. Ballantyne PJ. The role of pharmacists in primary care. $B M J$. 2007;334(7603):1066-1067.

14. Medication therapy management [webpage on the Internet]. Baltimore, MD: Centers for Medicare and Medicaid Services; 2014. Available from: http://www.cms.gov/Medicare/Prescription-DrugCoverage/PrescriptionDrugCovContra/MTM.html. Accessed June 20, 2014.

15. Denzin NK, Mettlin CJ. Incomplete professionalization: the case of pharmacy. Soc Forces. 1968;46(3):375-381.

16. Knowlton $\mathrm{CH}$. Pharmacy practice: where's the value proposition? Pharm Hist. 2009;51(3):94-97.

17. Brushwood DB. Recent trends in pharmacy law and regulation. Pharm Hist. 2009;51(3):98-102.

18. Eades CE, Ferguson JS, O'Carroll RE. Public health in community pharmacy: a systematic review of pharmacist and consumer views. BMC Public Health. 2011;11:582.

19. Davies JE, Barber N, Taylor D. What do community pharmacists do? Results from a work sampling study in London. Int J Pharm Pract. Epub January 14, 2014.

20. Basak SC, van Mil JW, Sathyanarayana D. The changing roles of pharmacists in community pharmacies: perception of reality in India. Pharm World Sci. 2009;31(6):612-618.

21. Gastelurrutia MA, Benrimoj SI, Castrillon CC, de Amezua MJ, Fernandez-Llimos F, Faus MJ. Facilitators for practice change in Spanish community pharmacy. Pharm World Sci. 2009;31(1):32-39.

22. Resnik DB, Ranelli PL, Resnik SP. The conflict between ethics and business in community pharmacy: what about patient counseling? J Bus Ethics. 2000;28(2):179-186.

23. Liberman JN, Hutchins DS, Shrank WH, Slezak J, Brennan TA. Adherence to medication under mandatory and voluntary mail benefit designs. Am J Manag Care. 2011;17(7):e260-e269.
24. Cutrona SL, Choudhry NK, Fischer MA, et al. Modes of delivery for interventions to improve cardiovascular medication adherence. Am J Manag Care. 2010;16(12):929-942.

25. Schlozman KL. What accent the heavenly chorus? Political equality and the American pressure system. J Politics. 1984;46(4): 1006-1032.

26. O'Brien JM. How nurse practitioners obtained provider status: lessons for pharmacists. Am J Health Syst Pharm. 2003;60(22):2301-2307.

27. Richmond TS, Thompson HJ, Sullivan-Marx EM. Reimbursement for acute care nurse practitioner services. Am J Crit Care. 2000;9(1): 52-61.

28. Spitz J, Wickham M. Pharmaceutical high profits: the value of R\&D, or oligopolistic rents? Am J Econ Sociol. 2012;71(1):1-36.

29. Quadagno J. Why the United States has no national health insurance: stakeholder mobilization against the welfare state, 1945-1996. J Health Soc Behav. 2004;45 Suppl:25-44.

30. Zellmer WA. Pharmacy's organizations - key issues for future historians. Pharm Hist. 2009;51(3):127-133.

31. Jorgensen PD. Pharmaceuticals, political money, and public policy: a theoretical and empirical agenda. J Law Med Ethics. 2013;41(3): 561-570.

32. About Pfizer [webpage on the Internet]. New York, NY: Pfizer; 2013. Available from: http://www.pfizer.com/about. Accessed April 14, 2014.

33. GSK: about us [webpage on the Internet]. Brentford: GlaxoSmithKline; 2012. Available from: http://us.gsk.com/html/about-us/index.html. Accessed April 14, 2014.

34. Pharmaceuticals [webpage on the Internet]. New Brunswick, NJ: Johnson and Johnson; 2014. Available from: http://www.jnj.com/aboutjnj/company-structure/pharmaceutical-companies. Accessed April 14, 2014.

35. Discover Roche [webpage on the Internet]. Basel: Hoffman-La Roche Ltd; 2014. Available from: http://www.roche.com/about_roche/ management/ceo_message.htm. Accessed April 14, 2014.

36. Bulow J. The gaming of pharmaceutical patents. In: Jaffe AB, Lerner J, Stern S, editors. Innovation Policy and the Economy, Volume 4. Cambridge, MA: The MIT Press; 2004:145-187.

37. Kendall B. DOJ shifts policy on generic drug patent settlements. The Wall Street Journal. 2009 July 6. Available from: http://online.wsj.com/ news/articles/SB124691728092502381. Accessed June 20, 2014.

38. Gray T, Bertch K, Galt K, et al. Guidelines for therapeutic interchange 2004. Pharmacotherapy. 2005;25(11):1666-1680.

39. Katz MH. Tobacco-free pharmacies: can we extend the ban? Tob Control. 2013;22(6):363-364.

40. Patwardhan P, McMillen R, Winickoff JP. Consumer perceptions of the sale of tobacco products in pharmacies and grocery stores among US adults. BMC Res Notes. 2013;6:261.

41. Seidenberg AB, Behm I, Rees VW, Connolly GN. Cigarette sales in pharmacies in the USA (2005-2009). Tob Control. 2012;21(5): 509-510.

42. Fincham JE. An unfortunate and avoidable component of American pharmacy: tobacco. Am J Pharm Educ. 2008;72(3):57.

43. Els C. Canada: pharmacy tobacco sales to mentally ill people. Tob Control. 2007;16(2):75.

44. Kotecki JE. Sale of alcohol in pharmacies: results and implications of an empirical study. J Community Health. 2003;28(1):65-77.

45. Latif DA. The relationship between pharmacists' tenure in the community setting and moral reasoning. J Bus Ethics. 2001;31(2): 131-141.

46. Smith MA, Bell HS, Kissack JC, Hall PD, Mackinnon GE, Lang WG. Report of the 2012-2013 standing committee on advocacy: advocacy tools and resources: a framework for increasing member engagement. Am J Pharm Educ. 2013;77(10):S17. 
Integrated Pharmacy Research and Practice

Dovepress

\section{Publish your work in this journal}

Integrated Pharmacy Research and Practice is an international, peer-reviewed, open access, online journal, publishing original research, reports, reviews and commentaries on all areas of academic and professional pharmacy practice. This journal aims to represent the academic output of pharmacists and pharmacy practice with particular focus on integrated care. All papers are carefully peer reviewed

Submit your manuscript here: http://www.dovepress.com/integrated-pharmacy-research-and-practice-journal to ensure the highest standards as well as ensuring that we are informing and stimulating pharmaceutical professionals. The manuscript management system is completely online and includes a very quick and fair peer-review system, which is all easy to use. Visit http://www.dovepress.com/testimonials.php to read real quotes from published authors. 